\title{
FÓRUM
}

Artigo convidado

Versão traduzida

DOI: http://dx.doi.org/10.1590/So034-759020210102

\section{HISTÓRIA, MEMÓRIA E PASSADO EM ESTUDOS ORGANIZACIONAIS E DE GESTÃO}

Nossos objetivos para este editorial são três. Primeiro, contextualizamos o crescente interesse dos estudiosos organizacionais e de gestão em questões de história, memória e do passado. Apesar do número crescente de estudos organizacionais históricos, o funcionalismo e o interpretativismo funcional continuam sendo as abordagens dominantes nos estudos organizacionais e de gestão (MOS, do inglês management and organization studies). Além disso, como os estudiosos europeus e norte-americanos estão excessivamente representados na literatura, a análise do impacto histórico do comércio global e das organizações multinacionais na relação entre o Norte e o Sul globais é limitada. Em segundo lugar, mapeamos a literatura que conecta história, memória e passado aos estudos organizacionais. Fornecemos uma visão geral dos esforços iniciais dos estudiosos de MOS para desenvolver abordagens humanistas para estudos organizacionais e discutir o papel que a história desempenha em informar discussões epistemológicas, teóricas, metodológicas e empíricas na área. Em terceiro, destacamos especificamente como os artigos desta edição especial contribuem para o campo da história e memória das organizações.

DIEGO M. CORAIOLA coraiola@ualberta.ca 0000-0003-2292-627X

\section{AMON BARROS 2,3} amon.barros@essex.ac.uk 0000-0002-9748-7788

\section{MAIRI MACLEAN ${ }^{4}$}

kmm57@bath.ac.uk 0000-0001-9030-7492

\section{WILLIAM M. FOSTER ${ }^{1}$} william.foster@ualberta.ca 0000-0002-9139-8434

1 University of Alberta, Augustana Faculty, Alberta, Canadá

2 University of Essex, Essex Business School, Colchester, Reino Unido

${ }^{3}$ Fundação Getulio Vargas, Escola de Administração de Empresas de São Paulo, São Paulo, Brasil

4University of Bath, School of Management, Bath, Reino Unido

\section{UMA BREVE HISTÓRIA DE ESTUDOS ORGANIZACIONAIS HISTÓRICOS}

Por mais de 30 anos, pesquisadores têm buscado reconectar história e estudos organizacionais. Tem sido uma subida íngreme desde que um grupo de pioneiros destacou que organizações são fenômenos históricos e elaborou uma agenda de pesquisa mais humanística (Zald, 1990, 1993), baseada na análise histórica e em uma compreensão mais profunda do contexto histórico e do passado (Kieser, 1994; Lawrence, 1984). 0 surgimento da "virada histórica" (Clark \& Rowlinson, 2004; Mills, Suddaby, Foster, \& Durepos, 2016) mudou nossa compreensão dos papéis desempenhados pelo passado, história e memória em MOS.

No entanto, apesar do crescente interesse em incorporar questões de tempo, memória e história em várias vertentes da pesquisa de MOS, existem algumas lacunas preocupantes. Primeiro, houve um envolvimento limitado de estudiosos com abordagens críticas e pós-modernas (Durepos, Shaffner, \& Taylor, no prelo). Especificamente, as abordagens pós-coloniais (Decker, 2013), descoloniais (Wanderley \& Barros, 2018) e ANTi-históricas (Durepos \& Mills, 2012) no estudo do passado não estão representadas na literatura MOS. Essas perspectivas também estão bem ausentes em edições especiais recentes sobre história, memória e o passado publicadas por periódicos centrais na área. À medida que a pesquisa motivada pela virada histórica amadurece, esperamos ideias acadêmicas cada vez mais ricas e diversificadas.

Em segundo lugar, grande parte da discussão sobre os estudos organizacionais históricos ocorreu na Europa e na América do Norte. Embora interesses semelhantes tenham sido expressos em outras partes do mundo (por exemplo, no Brasil), o número de publicações sobre o assunto não representa o número 
crescente de pesquisadores que buscam teorizar a intersecção entre a organização e passado. A falta de pesquisas além do Norte global é uma explicação para as discussões limitadas sobre a interação entre lugar e cultura, de um lado, e tempo, história e memória de outro. Para melhor explicar e explorar o impacto da virada histórica no conhecimento sobre gestão, precisamos produzir conhecimento de interesse geral que está embutido nas realidades locais. Em outras palavras, pesquisadores de gestão e organizações precisam dar-se conta de como o lugar molda a experiência do tempo para construir diferentes histórias. O Sul global tem suas próprias experiências para compartilhar; assim, é importante levar em consideração como as relações entre países e empresas de diferentes culturas e nacionalidades contribuiu para informar e transformar umas às outras.

Em terceiro, os centros de pesquisa internacionais de alta qualidade apresentam barreiras específicas para a divulgação de pesquisas conduzidas por estudiosos que não falam inglês. Restringir as comunicações a uma única língua prejudica a capacidade de pesquisadores não versados no idioma inglês de expressar seus pensamentos. Como a apresentação do passado não pode ser dissociada da linguagem e do vocabulário usados para vivenciar e falar dele, existem tradições de pesquisa ricas e especializadas em outros idiomas além do inglês que foram silenciadas e ignoradas. Isso tem limitado o alcance e o ritmo das pesquisas sobre questões importantes relacionadas à virada histórica.

Apesar dessas limitações, os estudos organizacionais históricos oferecem uma visão sobre os diferentes mecanismos de organizações e de gestão. Em particular, esses estudos iluminam fundamentos epistemológicos, teóricos, metodológicos e empíricos relacionados ao estudo do passado na pesquisa em MOS. Nas seções que se seguem revisamos brevemente essas discussões e destacamos algumas críticas atuais da área.

\section{Epistemológico}

Uma das principais críticas levantadas por acadêmicos da virada histórica tem sido o caráter a-histórico da maioria das pesquisas organizacionais e de gestão (Kieser, 1994; Zald, 1990). Tanto historiadores de negócios quanto estudiosos de organizações familiarizados com o uso de métodos históricos na pesquisa organizacional articularam essa crítica (Booth \& Rowlinson, 2006; Üsdiken \& Kieser, 2004). Como Clark e Rowlinson (2004) escreveram na época, a virada histórica "implicaria questionar a retórica cientificista dos estudos organizacionais, uma abordagem do passado como processo e contexto e não apenas como uma variável, e um engajamento com debates historiográficos, especialmente em relação ao status epistemológico da narrativa" (p. 346).

Outros também questionam como os princípios filosóficos da história impactam a pesquisa de MOS. Por exemplo, muitos projetos de pesquisa MOS adotam uma visão realista ingênua da história. O pressuposto de que existe uma correspondência direta entre a história e o passado foi dado como certo no MOS. Coraiola, Foster e Suddaby (2015), entretanto, argumentam que muitos projetos de pesquisa a-histórica, quando examinados mais de perto, são, na verdade, históricos. A diferença é que a maioria dos pesquisadores de MOS deixa de refletir sobre suas suposições tidas como certas sobre a história e o passado. Indo adiante, alguns estudiosos requisitaram aos pesquisadores ir além do conhecimento histórico (Kipping \& Üsdiken, 2014) com o intuito de desenvolver a consciência histórica (Suddaby, 2016).

Apesar desses esforços, os estudiosos de MOS continuam a ser criticados por seu envolvimento limitado com a história e o passado. Alguns notaram que as tentativas de integrar história e estudos organizacionais podem levar a um caminho em que a importância epistemológica da história é descartada. A triste consequência é que a história é tratada apenas como um método e/ou uma variável (Decker, 2016). Outros, particularmente estudiosos de estudos críticos em administração (ECA, do inglês critical management studies - CMS), argumentam que a intenção original da virada histórica foi apenas parcialmente cumprida. Como resultado, ainda há muito o que fazer para rejeitar a supremacia do cientificismo na teoria organizacional, reconhecer outros modos de estudar e representar o passado, e conceder legitimidade a formas heterogêneas de escrever história (Durepos et al., no prelo).

\section{Teórico}

Os estudiosos de MOS combinaram muito a história e o passado (Weatherbee, Durepos, Mills, \& Mills, 2012), conforme visto em duas abordagens principais de MOS. Uma abordagem é a pesquisa sobre imprinting e o estudo do efeito de eventos fundacionais passados em indivíduos, organizações e instituições atuais (como em Marquis, 2003; Marquis \& Tilcsik, 2013). O outro é o estudo da dependência do caminho e a noção de que ações no passado podem limitar ações possíveis no presente e no futuro (como em Sydow \& Schreyögg, 2013; Sydow, Schreyögg, \& Koch, 2009). Ambas as abordagens igualam o passado e o que ocorreu no passado com a história e como o passado é narrado.

Mais recentemente, esforços têm sido feitos para minimizar o determinismo dessas abordagens, redefinindo o 
passado e como ele é entendido nas organizações. Por exemplo, a lógica da sedimentação informou o conceito de imprinting. Ao invés de tratar o imprinting a partir da influência de evento antigo associado à fundação de uma organização, relatos mais recentes consideram a possibilidade de que eventos posteriores também possam ser fundamentais e criem diferentes camadas de efeitos geracionais (Marquis \& Tilcsik, 2013). Da mesma forma, os estudiosos da dependência do caminho redefiniram suas abordagens para incorporar caminhos não percorridos que ainda podem estar disponíveis como itens perdidos ou descartados (flotsam and jetsam), que potencialmente se tornam recursos endógenos para a mudança (Schneiberg, 2007). Ao igualar a história com o passado, ambas as abordagens deixam de explorar o que é verdadeiramente distinto na história. A história é importante porque é uma narrativa que impõe ordem e significado nas coisas passadas. Em outras palavras, as histórias que contamos sobre o passado o tornam significativo e administrável.

No entanto, a imprecisão da definição significa que narrativas e história são frequentemente consideradas as mesmas. Isso levou alguns estudiosos de MOS a confundir e interpretar mal a diferença entre construtos-chave, como história e memória coletiva. No entanto, quando examinados mais de perto, existem diferenças importantes e significativas entre os dois (Nora, 1989). Em termos metafóricos, a história é a narrativa contada por um explorador que está de fora, enquanto a memória coletiva é a lembrança de experiências compartilhadas. A história é o produto de pesquisas e escritas propositais que acontecem no presente olhando para o passado e que pressupõe descontinuidade e distância entre os atores do passado e os autores da história. A história tem, então, um autor identificável, cuja autoridade sobre o passado está ligada às fontes usadas para contar a narrativa.

A memória coletiva é distinta da história porque evolui de maneiras incertas e imprevisíveis. 0 que é lembrado (esquecido) é disseminado por meio de narrativas que são transmitidas (descartadas) de geração em geração. A memória coletiva é emergente e não tem um autor claro. 0 peso e a autoridade da memória coletiva são fornecidos por tradições e crenças de uma comunidade mnemônica específica (Zerubavel, 1996). História e memória, embora diferentes e distintas, podem ser pensadas como perspectivas alternativas do passado (Nora, 1989). Cada uma fornece descrições e interpretações complementares, contraditórias e correspondentes do passado, e sua interação requer melhor teorização por pesquisas futuras.

A concepção original da memória organizacional era como um repositório onde as informações passadas eram armazenadas para serem recuperadas para uso futuro (Walsh \& Ungson, 1991). Memória organizacional, portanto, foi entendida como o local onde as informações organizacionais eram armazenadas. A introdução da virada histórica, no entanto, levou ao questionamento da abordagem estática do local de armazenamento para a memória organizacional. Esse questionamento promoveu o desenvolvimento de uma abordagem mais dinâmica da memória organizacional, análoga às discussões sobre memória coletiva. As discussões sobre a memória organizacional logo foram redefinidas e tornou-se em particular geralmente aceita como um processo em vez de um local de armazenamento. Consequentemente, outros processos de organização da memória, como lembrar e esquecer (Feldman \& Feldman, 2006; Rowlinson, Booth, Clark, Delahaye, \& Procter, 2010), logo se tornaram tópicos relevantes para investigação.

A mudança de entendimento acerca da memória organizacional levou a novas discussões sobre como o passado é lembrado e esquecido e à emergência de um novo campo de pesquisa em Estudos Organizacionais da Memória (Foroughi, Coraiola, Rintamaki, Mena, Foster, In press). Debates acerca da memória também têm ocorrido em outras instâncias, em particular nas pesquisas em história retórica (Suddaby, Foster, \& Trank, 2010) e usos do passado (Wadhwani, Suddaby, Mordhorst, \& Popp, 2018). No entanto, história e memória permanecem em geral indistintos nesses trabalhos. Mais recentemente, acadêmicos chamaram a atenção para a necessidade de um engajamento mais reflexivo com a diferença entre os dois construtos (Decker, Hassard, Rowlinson, In press). Esforços nesse sentido devem levar a uma clareza maior das fronteiras entre eles e a uma melhor da contribuição específica da memória e da história para a nossa compreensão das organizações.

\section{Metodológico}

Vários pesquisadores tem sugerido o uso de métodos de pesquisa histórica e arquivística em MOS (como em Kieser, 1994; Lawrence, 1984; Ventresca \& Mohr, 2002). Na verdade, os estudiosos de MOS têm usado regularmente arquivos históricos como fonte de dados para o desenvolvimento de pesquisas empíricas. No entanto, para a maioria deles o passado era apenas um campo para se testar teorias. Havia pouco reconhecimento da importância do contexto, da crítica das fontes, da interpretação hermenêutica e do papel das notas de rodapé nas explicações históricas. Além disso, excetuando-se os estudos de um pequeno número de acadêmicos sintonizados com os debates e demandas específicas da pesquisa historiográfica (como em Rowlinson, 2004), a maioria dos estudos em MOS deixou de compreender totalmente o potencial da pesquisa arquivística e histórica. 
Duas publicações abriram novos caminhos ao introduzir mais vigorosamente uma compreensão histórica da pesquisa MOS. Rowlinson et al. (2014) esclareceram alguns pressupostos básicos sobre a pesquisa histórica e os contrastaram com os entendimentos tradicionais dos estudiosos de MOS. Da mesma forma, Bucheli e Wadhwani (2014) curaram uma coleção de artigos que exploram a conexão entre história e teoria em diferentes campos e abordagens, bem como alguns dos aspectos metodológicos que devem ser considerados na utilização de métodos históricos. Ambas as publicações uniram historiadores de negócios e estudiosos organizacionais em discussões comuns que ajudaram a fornecer orientação sobre o uso de métodos históricos em estudos organizacionais.

Discussões atuais têm ajudado em um maior engajamento metodológico com a história e seu papel nos estudos organizacionais. Por exemplo, Maclean, Harvey e Clegg $(2016,2017)$ mudaram essa discussão ao defenderem os estudos organizacionais históricos como um campo distinto e desenvolverem uma abordagem que busca integrar história e MOS. Eles redefiniram a relação entre pesquisa histórica e estudos organizacionais com base no conceito de "integridade dupla”, o que sugere que a história organizacional deve atender, simultaneamente, a critérios de pesquisa da história e dos estudos organizacionais. Outras tentativas de unir os dois campos se seguiram. Por exemplo, Gill, Gill e Roulet (2018) traduziram os critérios de confiabilidade a abordagem de Lincoln e Guba (1985) para investigação naturalística em elementos metodológicos históricos com o intuito de aumentar o apelo de narrativas históricas para um público de estudiosos organizacionais. Da mesma forma, Barros, Carneiro e Wanderley (2019) discutiram o papel da reflexividade na pesquisa arquivística e narrativas históricas, argumentando que a reflexividade é a chave para desvendar a natureza socialmente construída das fontes arquivísticas e estabelecer uma narrativa histórica como possível representação do passado.

\section{Empírico}

Estudiosos organizacionais históricos realizaram vários estudos empíricos. Por exemplo, exploraram tópicos como identidade organizacional (Anteby \& Molnár, 2012; Lamertz, Foster, Coraiola, \& Kroezen, 2016; Ravasi, Rindova, \& Stigliani, 2019; Schultz \& Hernes, 2013), mudança (Brunninge, 2009; Maclean, Harvey, Sillince, \& Golant, 2014; Ybema, 2014), legitimidade (Illia \& Zamparini, 2016; McGaughey, 2013; Voronov, Clercq, \& Hinings, 2013) e responsabilidade corporativa (Coraiola \& Derry, 2020; Lent
\& Smith, no prelo). Esse campo de pesquisa animador e em rápido crescimento tem muito a contribuir para o nosso conhecimento e compreensão de gestão e organizações.

A promessa de emancipação da história, no entanto, ainda está longe de ser realizada em MOS. Por exemplo, o crescente interesse na responsabilidade social corporativa histórica trouxe questões que estavam à margem para o primeiro plano de importância. Estudos requereram melhor compreensão da opressão como uma lição para o futuro (como em Martí \& Fernández, 2013; Sørensen, 2014). Por exemplo, Cooke (2003) argumentou persuasivamente em favor de mais pesquisas sobre a relação entre administração e escravidão. Godfrey, Hassard, O'Connor, Rowlinson e Ruef (2016) tomaram nota desse pedido e propuseram uma agenda para examinar a escravidão, seu papel nas políticas coloniais e as consequências dessas práticas para os casos de escravidão moderna.

Além disso, sugerimos que pesquisadores em MOS se concentrem em outras populações que foram afetadas pelo desenvolvimento das atividades coloniais e ainda carregam o peso desse passado. Um exemplo são as contribuições históricas de minorias, como afro-americanos (como em Prieto \& Phipps, 2016). Isso envolve intensificar a pesquisa sobre o impacto das relações coloniais em diferentes geografias, como América Latina (por exemplo, Wanderley \& Barros, 2018), África (por exemplo, George, Corbishley, Khayesi, Haas, \& Tihanyi, 2016) e Australásia (por exemplo, Mika \& O'Sullivan, 2014). Desenvolver uma agenda de pesquisa que estude os primeiros habitantes desses lugares é fundamental. As visões indígenas sobre o passado e a gestão também são pouco pesquisadas e até mesmo esquecidas (Bastien, Coraiola, \& Foster, 2021). Semelhante ao preconceito e à falta de condições de vida enfrentadas por descendentes de africanos, os povos indígenas têm estado amplamente ausentes da pesquisa em MOS, aparte raras exceções como Kennedy et al. (2017).

Outra importante área de pesquisa é o estudo de imigrantes e refugiados (Hardy \& Phillips, 1999; Phillips \& Hardy, 1997). Como outras minorias, eles enfrentam problemas que incluem deslocamento, preconceito, desigualdade e assimilação cultural. As circunstâncias históricas por trás da mobilidade de um grande número de pessoas geralmente são extremamente significativas e têm um impacto que pode durar muitas gerações. Por exemplo, existem relações históricas complexas entre imigrantes europeus, escravos traficados e populações nativas em países como o Brasil e os EUA, onde o preconceito histórico persiste e afeta profundamente as oportunidades existentes para descendentes de diferentes grupos sociais (por exemplo, Souza, 2003). Os estudos organizacionais históricos estão particularmente bem 
posicionados para esclarecer questões complexas que abrangem várias gerações.

\section{ARTIGOS NESTA EDIÇÃO ESPECIAL}

Um dos objetivos desta edição especial é fornecer um corretivo inicial para as discussões descritas acima. Para conseguir isso, convidamos artigos de várias matizes teóricas e ideológicas com o intuito de sermos inclusivos e podermos capturar as melhores contribuições para os estudos organizacionais históricos fora dos limites dos periódicos convencionais da área. Isso apela para a identidade da RAE como uma publicação proeminente do Sul global que sempre valorizou a diversidade de autoria e a variedade de abordagens teóricas. Os artigos revisados por colegas e ensaios convidados de conceituados acadêmicos brasileiros fornecem uma visão geral e crítica do estado atual da área. Estes cinco artigos, junto com nosso editorial, são indicativos da qualidade do conhecimento que está fora das publicações líderes da área e exemplificam o crescente envolvimento de estudiosos que estão abrindo caminho na divisão Norte-Sul.

Costa e Wanderley (2021) escreveram nosso ensaio convidado. Eles mostram como a história e a memória gradualmente se tornaram uma característica regular dos MOS no Brasil. Defendendo que já existe uma comunidade científica brasileira interessada no passado e seus usos, os autores examinam a expansão da literatura em gestão, memória e história desde os anos 2000. Eles revisitam os tópicos mais prevalentes e como eles se relacionam com a mais ampla virada histórica internacional. Os autores então concluem sugerindo como os estudiosos brasileiros podem contribuir para levar a virada histórica adiante.

Paludi, J. Mills, e A. Mills (2021) analisam os arquivos da Pan American Airways para revelar os discursos históricos da empresa sobre os latinos e a América Latina. Eles argumentam que a divisão colonial entre colonos ibéricos e britânicos informou como o povo latino-americano foi representado. Essas representações impactam a forma como os latino-americanos se veem e como são retratados em todo o mundo. Os autores falam do debate sobre a história como epistemologia em três níveis. Primeiro, eles apresentam um relato revisionista do passado com base na teoria feminista descolonial. Ao esclarecer sua episteme de antemão, eles revelam os fundamentos ideológicos de sua leitura do passado e abraçam uma abordagem alternativa para a pesquisa como uma declaração política. Em segundo lugar, eles reconhecem e se envolvem com a natureza narrativa da história, desenvolvendo esforços sistemáticos para desvendar as grandes narrativas e representações sociais que caracterizam o discurso histórico da Pan Am e da América Latina. Em terceiro, eles apresentam um caso significativo de uma empresa multinacional do Norte global que operava no Sul global. A discussão explora as consequências da narrativa e o impacto que isso tem na imagem e reputação internacional da América Latina.

Cappelen e Pedersen (2021) articulam habilmente como as organizações evitam a mudança da missão e a diluição da identidade explorando o passado. Os autores articulam três grandes construtos: foco temporal, lembrança e esquecimento organizacional e narrativas de identidade, para explicar como organizações podem permanecer fiéis a si mesmas à medida que passam pelas mudanças impostas pelas necessidades de recursos internos e pressões de acionistas externos. Eles descrevem como uma organização dinamarquesa sem fins lucrativos dedicada ao desenvolvimento de hortas escolares mudou seu foco temporal quando começou a se expandir. Os investimentos em crescimento e escala foram apoiados por narrativas que enfatizaram uma visão para o futuro em vez de conquistas passadas como sua identidade organizacional central. A mudança na missão da empresa e a existência de propósito organizacional incerto motivou os membros da organização a se engajarem novamente com o passado da organização e sua origem como organização sem fins lucrativos e a reformular suas narrativas de identidade em torno de um sentido mais amplo de propósito, abrangendo seu papel em sua atividade de hortas escolares. Analisando esse processo, os autores concluem que embora a memória seja um recurso importante que pode ser usado para criar narrativas de identidade, ela também fornece uma âncora temporal para evitar que as organizações se afastem de sua essência fundamental por causa de planos orientados para o futuro.

Tureta, Américo, e Clegg (2021) oferecem uma importante contribuição metodológica para o desenvolvimento da pesquisa ANTi-histórica. Eles argumentam que a análise de controvérsias oferece um caminho promissor para o estudo ANTi-histórico do passado. Em particular, os autores sugerem que o desenvolvimento de uma abordagem cartográfica para o mapeamento de controvérsias pode ser uma maneira útil de rastrear silêncios históricos e gerar uma compreensão mais completa das presenças e ausências contemporâneas. Eles oferecem quatro critérios principais que devem nortear a escolha das controvérsias a serem analisadas. Primeiro, os pesquisadores devem ser sensíveis às controvérsias do passado. Em segundo lugar, eles deveriam abraçar controvérsias "frias", isto é, controvérsias dadas como superadas e não mais geradoras 
polêmicas. Terceiro, eles devem se concentrar em controvérsias ocultas, que foram marginalizadas e silenciadas por outros atores poderosos. Quarto, eles devem ser cuidadosos ao abordar controvérsias sem limites, uma vez que analisá-las pode exigir grande esforço e muitos recursos. Os autores oferecem, então, uma série de etapas que podem ser seguidas no desenvolvimento da pesquisa ANTi-histórica com base na análise de controvérsias e no uso de abordagem cartográfica.

Silva, Vasconcelos, e Lira (2021) trazem importante contribuição sobre o papel das inscrições contábeis no processo de erradicação da escravidão no Brasil ao examinar a criação do Fundo Nacional de Emancipação dos escravos. Os autores analisam o uso do Fundo pelo governo brasileiro como mecanismo de governamentalidade. Ou seja, o governo criou o Fundo de Emancipação parcialmente para reduzir e minimizar o poder dos proprietários de escravos, tornando os escravos e seu trabalho visíveis. Ao fazer isso, o governo criou um caminho para uma transição gradual do trabalho escravo para o trabalho assalariado. Essa pesquisa histórica esclarece um importante mecanismo que contribuiu para o fim da escravidão no Brasil. Dessa forma, enriquece a literatura em história da contabilidade e contribui para a pesquisa sobre o uso da contabilidade como instrumento de governamentalidade. Além disso, oferece informações importantes sobre o uso da contabilidade como mecanismo institucional de mudança social que pode informar políticas futuras sobre a escravidão.

\section{Seguindo em frente}

Uma série de oportunidades surge à medida que a área dos estudos organizacionais históricos se desenvolve e amadurece. Uma maneira de avançar é encorajar os estudiosos a aumentar sua consciência sobre um campo comum de pesquisa entre os interessados em estudar o passado. Coraiola e Murcia (no prelo) argumentam que é hora de se envolver em discussões sobre "mnemônica organizacional". Isso implica discussões mais engajadas sobre os vários paradigmas de pesquisa histórica e uma crítica mais explícita da ingenuidade de algumas abordagens em estudar o passado. A reflexividade paradigmática pode ampliar nossa compreensão dos pressupostos e premissas históricas que informam os estudos organizacionais. Além disso, o envolvimento mais próximo entre estudiosos de diferentes comunidades de pesquisa dentro do campo da mnemônica organizacional pode levar a uma melhor compreensão das conexões entre os construtos relacionados, como conhecimento, memória e ignorância.
Aliado a isso, é importante reconhecer o papel periférico e sub-representado das abordagens críticas ao estudo do passado. Em comparação com as visões funcionalistas e interpretativas, há espaço para desenvolver e expandir abordagens críticas às organizações e à gestão. Publicações recentes têm clamado pelo desenvolvimento de uma história organizacional crítica. Durepos et al. (no prelo) reconheceram essa lacuna e ofereceram introspecções importantes para fazer o campo seguir adiante.

Como parte do propósito de desenvolver um campo mais diverso e inclusivo de estudos organizacionais históricos, também salientamos a necessidade de se reconhecer que tempo e espaço estão intrinsecamente conectados. Isso é central para abordagens descoloniais, como a proposta de Wanderley e Barros (2018), que argumenta que a geopolítica do conhecimento influencia a agenda dos estudos organizacionais históricos. Para combater essa imposição hegemônica, eles pedem por mais discussões das histórias regionais e encontros epistêmicos além das fronteiras. Um campo de pesquisa mais inclusivo será capaz de incentivar o desenvolvimento de novas ideias de pesquisadores antes excluídos dessas discussões. A criação de uma agenda mais aberta e diversa é consistente com a noção de “compreensão pluralista” defendida por Maclean et al. $(2016,2017)$. Esse conceito reconhece a riqueza de abordagens na área e promove uma abordagem mais igualitária para os estudos organizacionais históricos.

Outra possibilidade para estudos futuros que emerge de um engajamento mais reflexivo com o passado é o papel da história na educação gerencial. Afirmamos que a história é importante e deve ser ensinada nas escolas de negócios, mas o porquê e como a história deve ser ensinada para alunos de Administração não estão completamente claros. Por exemplo, a velha suposição de que o passado instrui o presente é questionada com base no fato de que a história não se repete. Isso exige reiterar o valor da história e da memória para a educação gerencial. Por exemplo, como um melhor entendimento global do desenvolvimento da educação em Administração pode contribuir para o desenvolvimento de alunos e educadores em Administração (Cummings \& Bridgman, 2016)? A proposta de Cummings, Bridgman, Hassard e Rowlinson (2017) para uma nova história da Administração oferece algumas sugestões. Os autores usam uma lente crítica para revisitar a história da Administração, historicizando construtos importantes dentro do campo da Administração. Eles argumentam que precisamos entender as origens do pensamento em Administração para evitar a reprodução de preconceitos históricos e mal-entendidos - por exemplo, a pirâmide de Maslow (Bridgman, Cummings, \& Ballard, 2019) - como uma forma de desenvolver entendimentos alternativos sobre o papel de mudança da gestão na sociedade. 
Da mesma forma, existem vários esforços para compreender a disseminação global das ideias de gestão e difusão das escolas de negócios. Por exemplo, Cooke e Alcadipani (2015) mostraram como a introdução das escolas de negócios no Brasil foi resultado de um movimento mais amplo pela americanização da educação gerencial. Maclean, Shaw, Harvey e Booth (2020) esclareceram o desenvolvimento da educação gerencial britânica e o papel das redes de conhecimento e comunidades de prática na formação do aprendizado gerencial na Grã-Bretanha entre as guerras. Ambos sugerem que os princípios do excepcionalismo americano não foram tão prontamente aceitos como comumente assumido, mas foram desafiados e traduzidos para essas diferentes realidades. Esses estudos fornecem uma orientação importante para pesquisas futuras e também têm relevância para a prática de gestão. Como Tennent, Gillett e Foster (2020) argumentam, os alunos devem estar mais cientes da história da área e ser capazes de desenvolver uma consciência histórica. Isso exige uma abordagem mais dinâmica da história e das narrativas que enquadram a forma como percebemos o passado. Uma compreensão aprimorada do passado e sua conexão com a história e a memória podem, assim, contribuir para um ideal mais emancipatório de pesquisa histórica de MOS.

Para concluir, o objetivo desta edição especial é promover maior pluralismo e inclusão nos estudos organizacionais históricos. Os artigos desta edição abordam uma série de questões-chave, como a importância do lugar em que a história se desenrolou, a importância do trabalho de estudiosos do Sul global e as críticas as abordagens funcionalistas existentes para a gestão e os estudos organizacionais. Embora seja apenas um começo, os estudos nesta edição contribuem coletivamente para uma agenda contínua e pluralista para pesquisas interessadas na conexão entre passado e estudos organizacionais.

\section{REFERÊNCIAS}

Anteby, M., \& Molnár, V. (2012). Collective memory meets organizational identity: Remembering to forget in a firm's rhetorical history. Academy of Management Journal, 55(3), 515-540. doi: 10.5465/amj.2010.0245

Barros, A., Carneiro, A. D. T., \& Wanderley, S. (2019). Organizational archives and historical narratives: Practicing reflexivity in (re) constructing the past from memories and silences. Qualitative Research in Organizations and Management: An International Journal, 14(3), 280-294. doi/10.1108/QROM-01-2018-1604

Bastien, F., Coraiola, D. M., \& Foster, W. M. (2021). Don’t talk about history: Theorizing 'past occurrences' in Indigenous organizations. In M. Maclean, S.R. Clegg, R. Suddaby, \& C. Harvey (Eds), Historical organization studies: Theory and applications (pp. 90-103).. Routledge. doi: 10.4324/9781003033592-6.
Booth, C., \& Rowlinson, M. (2006). Management and organizational history: Prospects. Management \& Organizational History, 1(1), 5-30. doi: $10.1177 / 1744935906060627$

Bridgman, T., Cummings, S., \& Ballard, J. (2019). Who built Maslow's pyramid? A history of the creation of management studies' most famous symbol and its implications for management education. Academy of Management Learning \& Education, 18(1), 81-98. doi: 10.5465/amle.2017.0351

Brunninge, O. (2009). Using history in organizations: How managers make purposeful reference to history in strategy processes. Journal of Organizational Change Management, 22(1), 8-26. doi: 10.1108/09534810910933889

Bucheli, M., \& Wadhwani, R. D. (Eds.). (2014). Organizations in time: History, theory, methods. Oxford, UK: Oxford University Press.

Cappelen, S. M \& Pedersen, S. M (2021). Hijacked by hope: Dynamics of mission drift and identity dilution in a nonprofit organization. RAE-Revista de Administração de Empresas, 61(1): e2019-0432. doi: 10.1590/So034-759020210104

Clark, P., \& Rowlinson, M. (2004). The treatment of history in organisation studies: Towards an 'historic turn'? Business History, 46(3), 331-352. doi: $10.1080 / 0007679042000219175$

Cooke, B. (2003). The denial of slavery in management studies. Journal of Management Studies, 40(8), 1895-1918. doi: 10.1046/j.14676486.2003.00405.x

Cooke, B., \& Alcadipani, R. (2015). Toward a global history of management education: The case of the Ford Foundation and the São Paulo School of Business Administration, Brazil. Academy of Management Learning \& Education, 14(4), 482-499. doi: 10.5465/amle.2013.0147

Coraiola, D. M., \& Derry, R. (In press). Remembering to forget: The historic irresponsibility of U.S. Big tobacco. Journal of Business Ethics, 166(2), 233-252. doi: 10.1007/s10551-019-04323-4.

Coraiola, D. M., Foster, W. M., \& Suddaby, R. (2015). Varieties of history in organization studies. In P. G. McLaren, A. J. Mills, \& T. G. Weatherbee (Eds.), The Routledge Companion to management \& organizational history (pp. 206-221). New York, USA: Routledge.

Coraiola, D. M., \& Murcia, M. J. (2020). From organizational learning to organizational mnemonics: Redrawing the boundaries of the field. Man agement Learning, 42(4): 439-446. doi: 10.1177/1350507619889737

Costa, A. S. M \& Wanderley, S. (2021). Passado, presente e futuro de história (crítica) das organizações no Brasil. RAE-Revista de Administração de Empresas, 61(1): e2021-0103. doi: 10.1590/So034759020210107

Cummings, S., \& Bridgman, T. (2016). The limits and possibilities of history: How a wider, deeper, and more engaged understanding of business history can foster innovative thinking. Academy of Management Learning \& Education, 15(2), 250-267. doi: 10.5465/amle.2014.0373

Cummings, S., Bridgman, T., Hassard, J., \& Rowlinson, M. (2017). A new history of management. Cambridge, UK: Cambridge University Press.

Decker, S. (2013). The silence of the archives: Business history, postcolonialism and archival ethnography. Management \& Organizational History, 8(2), 155-173. doi: 10.1080/17449359.2012.761491

Decker, S. (2016). Paradigms lost: Integrating history and organization studies. Management \& Organizational History, 11(4), 364-379. doi: 10.1080/17449359.2016.1263214 
Decker S, Hassard J, Rowlinson M. (In press). Rethinking history and memory in organization studies: The case for historiographical reflexivity. Human Relations. doi: 10.1177/0018726720927443

Durepos, G., \& Mills, A. J. (2012). Actor-network theory, ANTi-History and critical organizational historiography. Organization, 19(6), 703-721. doi: $10.1177 / 1350508411420196$

Durepos, G., Shaffner, E. C., \& Taylor, S. (In press). Developing critical organizational history: Context, practice and implications. Organization, oo(o), 1-9. doi/10.1177/1350508419883381

Feldman, R. M., \& Feldman, S. P. (2006). What links the chain: An essay on organizational remembering as practice. Organization, 13(6), 861. 887. doi: $10.1177 / 1350508406068500$

Foroughi, H., Coraiola, D. M., Rintamaki, J., Mena, S., Foster, W. M. (In press). Organizational Memory Studies. Organization Studies. doi: 10.1177/0170840620974338

George, G., Corbishley, C., Khayesi, J. N. O., Haas, M. R., \& Tihanyi, L. (2016). Bringing Africa in: Promising directions for management research. Academy of Management Journal, 59(2), 377-393. doi: 10.5465/amj.2016.4002

Gill, M. J., Gill, D. J., \& Roulet, T. J. (2018). Constructing trustworthy historical narratives: Criteria, principles and techniques. British Journal of Management, 29(1), 191-205. doi: 10.1111/1467-8551.12262

Godfrey, P. C., Hassard, J., O’Connor, E. S., Rowlinson, M., \& Ruef, M. (2016). What is organizational history? Toward a creative synthesis of history and organization studies. Academy of Management Review, 41(4), 590-608. doi: 10.5465/amr.2016.0040

Hardy, C., \& Phillips, N. (1999). No joking matter: Discursive struggle in the Canadian refugee system. Organization Studies, 20(1), 1-24. doi: $10.1177 / 0170840699201001$

Illia, L., \& Zamparini, A. (2016). Legitimate distinctiveness, historical bricolage, and the fortune of the commons. Journal of Management Inquiry, 25(4), 397-414. doi: 10.1177/1056492616637917

Kennedy, D. M., Harrington, C. F., Verbos, A. K., Stewart, D., Gladstone, J. S., \& Clarkson, G. (2017). American Indian business: Principles and practices. Seattle, USA: University of Washington Press.

Kieser, A. (1994). Why organization theory needs historical analyses: And how this should be performed. Organization Science, 5(4), 608 620. doi: 10.1287 /orsc.5.4.608

Kipping, M., \&Üsdiken, B. (2014). Historyin organizationand management theory: More than meets the eye. The Academy of Management Annals, 8(1), 535-588. doi: 10.1080/19416520.2014.911579

Lamertz, K., Foster, W. M., Coraiola, D. M., \& Kroezen, J. (2016). New identities from remnants of the past: An examination of the history of beer brewing in Ontario and the recent emergence of craft breweries. Business History, 58(5), 796-828. doi: 10.1080/00076791.2015.1065819

Lawrence, B. S. (1984). Historical perspective: Using the past to study the present. The Academy of Management Review, 9(2), 307-312. doi: 10.5465/amr.1984.4277663

Lent, W. Van, \& Smith, A. D. (In press). Using versus excusing: The Hud son's Bay company's long-term engagement with its (problematic) past. Journal of Business Ethics. Retrieved from: https://link.spring er.com/content/pdf/10.1007/s10551-019-04320-7.pdf

Lincoln, Y. S., \& Guba, E. G. (1985). Naturalistic inquiry. Beverly Hills, USA: Sage Publications.
Maclean, M., Harvey, C., \& Clegg, S. R. (2016). Conceptualizing historical organization studies. Academy of Management Review, 41(4), 609632. doi: 10.5465/amr.2014.0133

Maclean, M., Harvey, C., \& Clegg, S. R. (2017). Organization theory in business and management history: Current status and future prospects. Business History Review, 91(3), 457-481. doi: 10.1017/ So007680517001027

Maclean, M., Harvey, C., Sillince, J. A. A., \& Golant, B. D. (2014). Living up to the past? Ideological sensemaking in organizational transition. Organization, 21(4), 543-567. doi: 10.1177/1350508414527247

Maclean, M., Shaw, G., Harvey, C., \& Booth, A. (2020). Management learning in historical perspective: Rediscovering Rowntree and the British interwar management movement. Academy of Management Learning \& Education, 19(1), 1-20. doi: 10.5465/amle.2018.0301

Marquis, C. (2003). The pressure of the past: Network imprinting in intercorporate communities. Administrative Science Quarterly, 48(4), 655-689. doi: $10.2307 / 3556640$

Marquis, C., \& Tilcsik, A. (2013). Imprinting: Toward a multilevel theory. The Academy of Management Annals, 7(1), 195-245. doi: 10.5465/19416520.2013.766076

Martí, I., \& Fernández, P. (2013). The Institutional Work of Oppression and Resistance: Learning from the Holocaust. Organization Studies, 34(8), 1195-1223. doi: 10.1177/0170840613492078

McGaughey, S. L. (2013). Institutional entrepreneurship in North American lightning protection standards: Rhetorical history and unintended consequences of failure. Business History, 55(1), 73-97. doi: 10.1080/00076791.2012.687537

Mika, J. P., \& O'Sullivan, J. G. (2014). A Māori approach to management: Contrasting traditional and modern Māori management practices in Aotearoa New Zealand. Journal of Management \& Organization, 2o(5), 648-670. doi: /10.1017/jmo.2014.48

Mills, A. J., Suddaby, R., Foster, W. M., \& Durepos, G. (2016). Re-visiting the historic turn 10 years later: Current debates in management and organizational history - an introduction. Management \& Organizational History, 11(2), 67-76. doi: 10.1080/17449359.2016.1164927

Nora, P. (1989). Between memory and history: Les lieux de Memoire. Representations, 26(Spring), 7-24.

Paludi, M. I., Mills, J. H. \& Mills, A. J. (2021). Corporate storytelling and the idea of Latin America. RAE-Revista de Administração de Empresas, 61(1): e2019-0462. doi: 10.1590/So034-759020210103

Phillips, N., \& Hardy, C. (1997). Managing multiple identities: Discourse, legitimacy and resources in the UK refugee system. Organization, 4(2), 159-185. doi: 10.1177/135050849742002

Prieto, L. C., \& Phipps, S. T. A. (2016). Re-discovering Charles Clinton Spaulding's "The Administration of Big Business": Insight into early 2oth century African-American management thought. Journal of Management History, 22(1), 73-90. doi: doi/10.1108/JMH-01-20150004

Ravasi, D., Rindova, V., \& Stigliani, I. (2019). The stuff of legend: History, memory, and the temporality of organizational identity construction. Academy of Management Journal, 62(5), 1523-1555. doi: 10.5465/ amj.2016.0505 
Rowlinson, M. (2004). Historical analysis of company documents. In C. Cassell, \& G. Symon (Eds.), Essential guide to qualitative methods in organizational research (pp. 301-311). London, UK: SAGE Publications.

Rowlinson, M., Booth, C., Clark, P., Delahaye, A., \& Procter, S. (2010). Social remembering and organizational memory. Organization Studies, 31(1), 69-87. doi: 10.1177/0170840609347056

Schneiberg, M. (2007). What's on the path? Path dependence, organizational diversity and the problem of institutional change in the US economy, 1900-1950. Socio-Economic Review, 5(1), 47-80. doi: $10.1093 / \mathrm{ser} / \mathrm{mwloo6}$

Schultz, M., \& Hernes, T. (2013). A temporal perspective on organizational identity. Organization Science, 24(1), 1-21. doi: 10.1287/ orsc.1110.0731

Silva, A. R., Vasconcelos, A., \& Lira, T. A (2021). Inscrições contábeis para o exercício do poder organizacional: 0 caso do fundo de emancipação de escravos no Brasil. RAE-Revista de Administração de Empresas, 61(1): e2019-0448. doi: 10.1590/So034-759020210106

Sørensen, B. M. (2014). Changing the memory of suffering: An organizational aesthetics of the dark side. Organization Studies, 35(2), 279-302. doi: 10.1177/0170840613511930

Souza, J. (2003). A construção social da subcidadania: Para uma sociologia política da modernidade periférica. Belo Horizonte, MG: Editora UFMG.

Suddaby, R. (2016). Toward a historical consciousness: Following the historic turn in management thought.M@n@gement: Revue officielle de l'Association Internationale de Management Stratégique, 19(1), 46-60. doi:10.3917/mana.191.0046

Suddaby, R., Foster, W. M., \& Trank, C. Q. (2010). Rhetorical history as a source of competitive advantage. In J. A. C. Baum, \& J. Lampel (Eds.), Advances in strategic management: The globalization of strategy research (pp. 147-173). Bingley, UK: Emerald.

Sydow, J., \& Schreyögg, G. (2013). Self-reinforcing processes in and among organizations. Hampshire, UK: Palgrave.

Sydow, J., Schreyögg, G., \& Koch, J. (2009). Organizational path dependence: Opening the black box. Academy of Management Review, 34(4), 689-709. doi: 10.5465/amr.34.4.zok689

Tennent, K. D., Gillett, A. G., \& Foster, W. M. (2020). Developing historical consciousness in management learners. Management Learning, 51(1), 73-88. doi: 10.1177/1350507619869669
Tureta, C. Américo, B. \&Clegg, S. (2021). Controversies as method for anti-history. RAE-Revista de Administração de Empresas, 61(1): e2019-0457. doi: 10.1590/So034-759020210105

Üsdiken, B., \& Kieser, A. (2004). Introduction: History in organisation studies. Business History, 46(3), 321-330.

Ventresca, M., \& Mohr, J. (2002). Archival research methods. In J. A. C. Baum (Ed.), The Blackwell Companion to organizations. Oxford, USA: Blackwell.

Voronov, M., Clercq, D. De, \& Hinings, C. R. (2013). Conformity and distinctiveness in a global institutional framework: The legitimation of Ontario fine wine. Journal of Management Studies, 50(4), 607-645. doi: $10.1111 /$ joms.12012

Wadhwani, R. D., Suddaby, R., Mordhorst, M., \& Popp, A. (2018). History as organizing: Uses of the past in organization studies. Organization Studies, 39(12), 1663-1683. doi: 10.1177/0170840618814867

Walsh, J. P., \& Ungson, G. R. (1991). Organizational memory. The Academy of Management Review, 16(1), 57-91. doi: 10.5465/amr.1991.4278992

Wanderley, S., \& Barros, A. (2018). Decoloniality, geopolitics of knowledge and historic turn: Towards a Latin American agenda. Management \& Organizational History, 14(1), 79-97. doi: $10.1080 / 17449359.2018 .1431551$

Weatherbee, T. G., Durepos, G., Mills, A., \& Mills, J. H. (2012). Theorizing the past: Critical engagements. Management \& Organizational History, 7(3), 193-202. doi: 10.1177/1744935912444358

Ybema, S. (2014). The invention of transitions: History as a symbolic site for discursive struggles over organizational change. Organization, 21(4), 495-513. doi: 10.1177/1350508414527255

Zald, M. N. (1990). History, sociology and theories of organization. In J. E. Jackson (Ed.), Institutions in American society: Essays in market, political, and social organizations (pp. 81-108). Ann Arbor, USA: University of Michigan Press.

Zald, M. N. (1993). Organization studies as a scientific and humanistic enterprise: Toward a reconceptualization of the foundations of the field. Organization Science, 4(4), 513-528. doi: 10.1287/orsc.4.4.513

Zerubavel, E. (1996). Social memories: Steps to a sociology of the past. Qualitative Sociology, 19(3), 283-299. doi: 10.1007/BF02393273

\section{CONTRIBUIÇÃO DOS AUTORES}

Os autores declaram que todos tiveram contribuição no desenvolvimento do estudo. Todos trabalharam na conceitualização e abordagem teórica-metodológica, revisão teórica e participaram da redação e revisão final do manuscrito. 